\title{
A Literature Review on Reducing the Warpage of Plastic Component by using Taguchi Optimization Technique, Gate location and Direction of Polishing on Core and Cavity
}

\author{
Mr. Ravi B Chikmeti ${ }^{1}$, Prof. Sunil Mangshetty ${ }^{2}$ \\ ${ }^{1}$ M.Tech. (PE), Mechanical Engineering Dept., PDA College of Engineering and Technology, Gulbarga, \\ ${ }^{2}$ Mechanical Engineering Dept., PDA College of Engineering and Technology, Gulbarga, Karnataka, India
}

\begin{abstract}
A competent mould designer must have a thorough knowledge of the principles of mould making as the design of the various parts of the mould depends on the technique adopted for its manufacture. This paper deals with the literature review on study of application of taguchi method and suitable finishing of core and cavity, and proper gate location which will reduce the maximum war page of the plastic injection molding/component. Injection molding is a major part of the plastics industry and is a big business worldwide. It is a widely used polymer processing method due to its high production rate, low cost and capability to produce intricate Parts with high precision. It is much difficult to set optimal process parameter levels which may cause defects in articles, such as shrinkage.
\end{abstract}

Keywords: Plastic injection molding, Taguchi method/OA table, Gate location and direction of polish

\section{Introduction}

Warpage of plastic products is a deviation from the shape of the mold cavity, which is one of the common pitfalls of plastic products. There are many reasons for warpage, process parameters alone is often powerless to solve. With relevant information and practical experience, the following injection of Warpage of a brief analysis of factors. Second, the structure of die warpage of injection molding products. In the mold, the plastic deformation of the main factors gating system, cooling system and ejection system. Injection molding represents one of the most important processes in the mass production of manufactured plastic parts with complex geometries. The quality of the injection moldings depends on the material characteristics, the mold design and the process conditions [1,2].Defects in the dimensional stability of the parts result in shrinkage. In order to minimize such defects in plastic injection molding, design of experiment, the Taguchi method is applied. In experimental design, there are many variable factors that affect the functional characteristics of the product. Design parameter values that minimize the effect of noise factors on the product's quality are determined. In order to find optimum levels, fractional factorial designs using orthogonal arrays are used. In this way, an optimal set of process conditions can be obtained from very few experiments [3, 4].
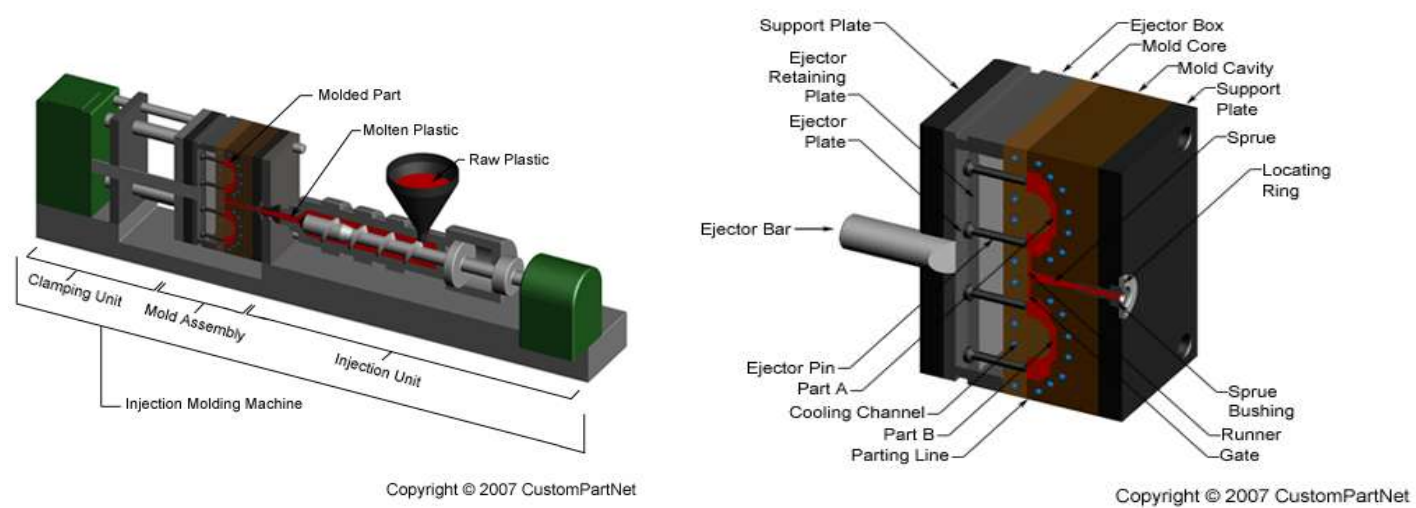

Fig 1: Plastic Injection Molding

\subsection{Taguchi Technique:}

Taguchi techniques were developed by Dr. Genichi Taguchi. Taguchi developed the foundations of robust design and validated its basic philosophies by applying them in the development of many products (Phadke, 1989). Taguchi method can be used for optimization methodology that improves the quality of existing products and processes and simultaneously reduces their costs very rapidly, with minimum engineering resources and development man-hours. It achieves this objective by making the product or process performance 
"insensitive" to variations in factors such as materials, manufacturing equipment, workmanship and operating conditions. It also makes the product or process robust and therefore it is called as robust design. All man-made machines or set-up are classified as engineering systems according to Taguchi. Engineering systems can be classified in to two categories: Static and Dynamic.

Dynamic system has signal factors (input from the end user) in addition to control and noise factors, whereas in static system signal factors are not present. Optimization of injection molding process is a static system (Refer Figure 2). Figure 2 is called the P-diagram. The ' $\mathrm{P}$ ' means process or product according to Taguchi [6].

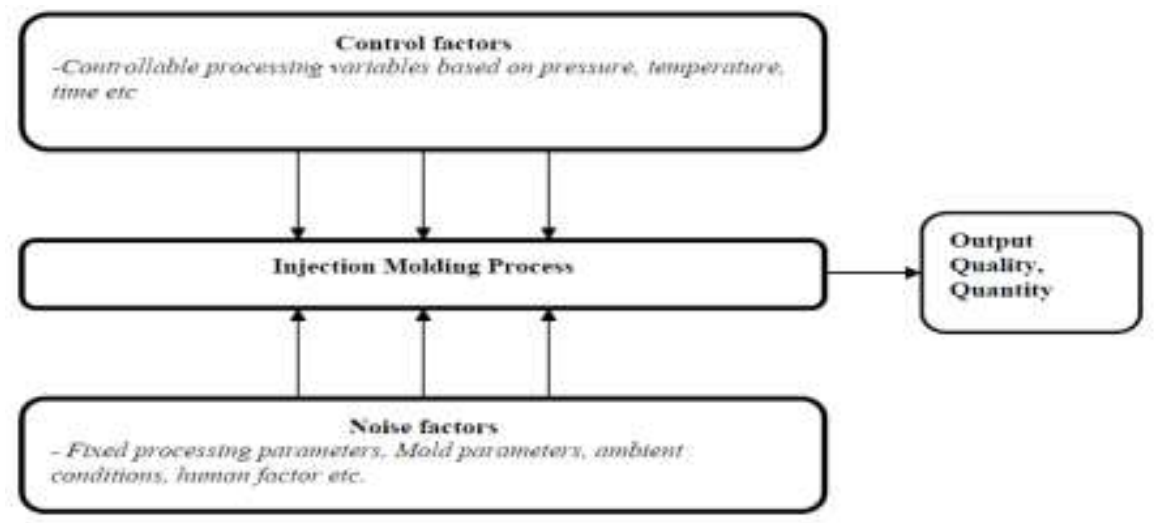

Figure 2 . P-diagram of injection molding process

\subsubsection{Design of Experiments (DOE):}

The DOE procedure consists of the following four steps :

Planning: definition of the problem and the objective, and development of an experimental plan.

Screening: reduction of the number of variables by identifying the key variables that affect product quality.

Optimization: determination of the optimal values for various experimental factors.

Verification: performing a follow-up experiment at the predicted best processing conditions to confirm the optimization, results.In this study, parameter design is coupled to achieve the optimum levels of process parameters leading to minimum shrinkage during the manufacturing of plastic parts.

\subsubsection{Steps in Taguchi Parameter Design}

In this study, Taguchi parameter design was used for identifying the significant processing parameters and optimizing the minimum shrinkage. Two important tools used in parameter design are orthogonal arrays and signal-to-noise $(\mathrm{S} / \mathrm{N})$ ratios. Fig. 3. demonstrates the steps of Taguchi parameter design .

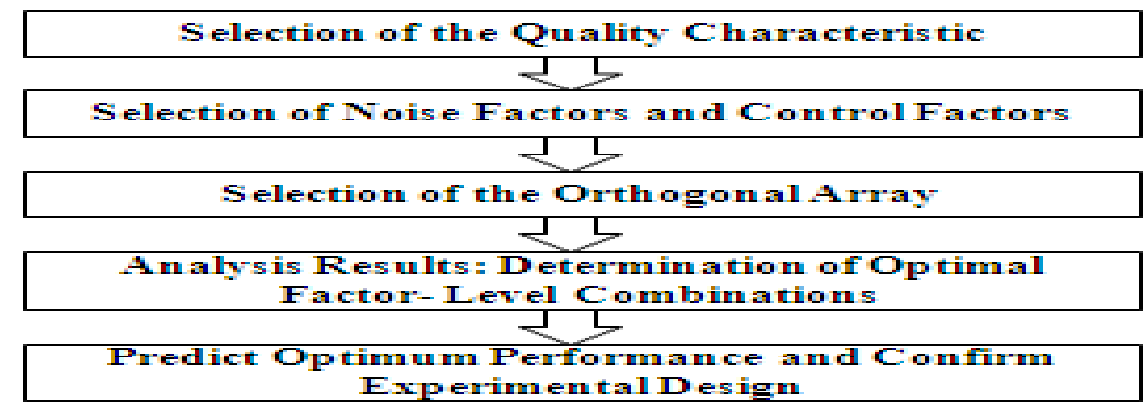

Figure 3: Steps of Taguchi Parameter Design.

\subsubsection{Selection of the quality characteristic}

There are three types of quality characteristics in the Taguchi methodology such as the-smaller-thebetter, the-larger the-better, and the-nominal-the-best. Signal to Noise analysis is designed to measure quality characteristic. It is given

$\mathrm{S} / \mathrm{N}=\mathbf{- 1 0} \log _{10}(\mathrm{MSD})$

Where MSD = Mean Square Deviation

For the smaller the better characteristic, MSD $=\left(\mathbf{Y}_{1}{ }^{2}+\mathbf{Y}_{2}{ }^{2+} \mathbf{Y}_{3}{ }^{2}+\cdots \cdots . . ..\right) / \mathbf{n}$

For the larger the better characteristic, 
$\mathrm{MSD}=\left(1 / \mathrm{Y}_{1}{ }^{2}+1 / \mathrm{Y}_{2}{ }^{2}+1 / \mathrm{Y}_{3}{ }^{2}\right.$ ..) / $\mathbf{n}$

For the nominal the best characteristic, $\mathbf{M S D}=\left[\left(\mathbf{Y}_{1}-\mathbf{m}\right)^{2}+\left(\mathbf{Y}_{1}-\mathbf{m}\right)^{2}+\left(\mathbf{Y}_{1}-\mathbf{m}\right)^{2}+\right.$ ..)]/n

Where $\mathrm{Y} 1, \mathrm{Y} 2, \mathrm{Y} 3$ are the responses and $\mathrm{n}$ is the number of tests in a trial and $\mathrm{m}$ is the target value of the result . Smaller shrinkage values represent better or improved minimum shrinkage.

\section{Literature Review:}

[5]. Mr. A.J. Yadav1, Mrs. S.V. Dravid2 Mr. V.D. Rajput3,taguchi technique in optimization of injection molding process parameters for manufacturing plastic parts, Proceedings of the NCNTE-2012, Third Biennial National Conference on Nascent Technologies Fr. C. Rodrigues Institute of Technology, Vashi, Navi Mumbai, Feb 24-25, 2012 Department of Mechanical Engineering.

Materials: Polypropylene (PP) and Acrylonitrile butadiene styrene (ABS) were used for this study. Injection Molding Process:

A specimen (Fig.) was injection molded with a 100-ton injection molding machine (Electronica), which performs the injection process by adjusting the experimental parameters via a control program. Materials were dried for $2 \mathrm{~h}$ at $800 \mathrm{C}$ prior to injection.

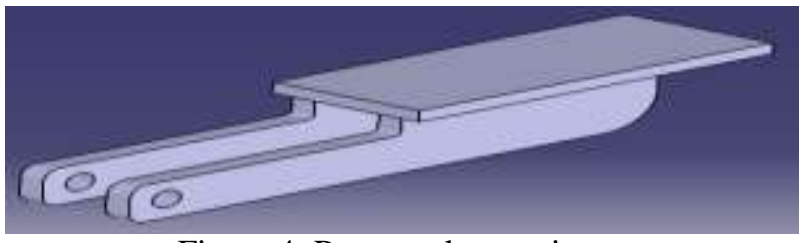

Figure 4: Rectangular specimen.

\section{Shrinkage measurement:}

Shrinkage is the difference between the size of a mold cavity and the size of the finished part divided by the size of a mold. Usually it is expressed in percentage. Four points were marked on the specimen, and measurements were made with digital calipers (with an accuracy of $0.01 \mathrm{~mm}$ ). For each specimen, the average thickness was calculated as the arithmetic mean of the four points. The relative shrinkage was determined as $\mathbf{S}=\left(\mathbf{D}_{\mathrm{m}}-\mathbf{D}_{\mathrm{P}) / \mathbf{D}_{\mathrm{m}}} \mathbf{X} \mathbf{1 0 0 \%}\right.$ where $\mathrm{S}$ denotes the shrinkage, Dm denotes the mold dimension and Dp denotes the part dimension.

Table : Controllable factors and levels

\begin{tabular}{|c|c|c|c|}
\hline Factors & Level I & Level 2 & Level 3 \\
\hline Melt Temperature, A ( $\left.{ }^{\circ} \mathrm{C}\right)$ & 200 & 210 & 220 \\
\hline Injection Pressure, B (MPa) & 60 & 70 & 80 \\
\hline Packing Pressure, C (MPa) & 40 & so & 60 \\
\hline Packing Time, D (S) & 5 & 10 & 15 \\
\hline Cooling Time, $\mathrm{E}$ (S) & 4 & 6 & 8 \\
\hline
\end{tabular}

By the literature review,it is observed that,The highest $\mathrm{S} / \mathrm{N}$ ratio for each factor gave the optimal process conditions, which corresponds to a melt temperature of $220{ }^{0} \mathbf{C}$, an injection pressure of $70 \mathrm{MPa}$, a packing pressure of $60 \mathrm{MPa}$, a packing time of $15 \mathrm{~s}$, cooling time $4 \mathrm{~s}$. and a melt temperature of $2200 \mathrm{C}$, an injection pressure of $70 \mathrm{MPa}$, a packing pressure of $60 \mathrm{MPa}$, a packing time of $10 \mathrm{~s}$ and cooling time $8 \mathrm{~s}$ for the material PP and ABS, respectively.

[4]. S. Kamaruddin, Zahid A. Khan and S. H. Foong, Application of Taguchi Method in the Optimization of Injection Moulding Parameters for Manufacturing Products from Plastic Blend, IACSIT International Journal of Engineering and Technology, Vol.2, No.6, December 2010 ISSN: 1793-8236.

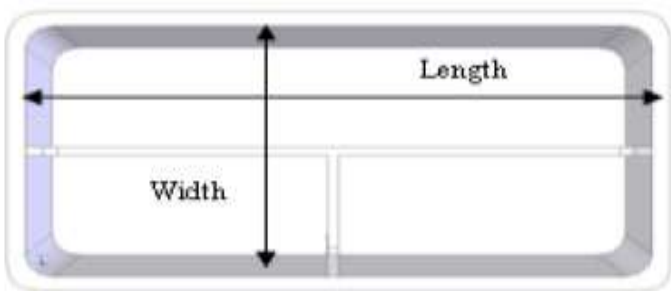

\begin{tabular}{|c|c|c|c|c|c|}
\hline Factor & Parameter & Unit & Level 1 & Level 2 & Level 3 \\
\hline A & Injection Speed & ipm (\%) & 80 & 90 & - \\
\hline B & Melung Temperature & ${ }^{\circ} \mathrm{C}$ & 220 & 230 & 240 \\
\hline C & Injection Pressure & bar & 100 & 110 & 120 \\
\hline D & Holding Pressure & bax & 80 & 88 & 96 \\
\hline$E$ & Holding Time & $\sec$. & 5 & 8 & 10 \\
\hline $\mathrm{F}$ & Cooling Time & sec. & 5 & 8 & 10 \\
\hline
\end{tabular}

Figure5: The length and width of the plastic tray 
- The optimum conditions are injection speed $(90 \% \mathrm{rpm})$, melting temperature $\left(\mathbf{2 4 0}^{\circ} \mathbf{C}\right)$, injection pressure (110 bar), holding pressure (96 bar), holding time ( $5 \mathrm{sec})$, and cooling time $(10 \mathrm{sec})$.

- Melting temperature is the most significant parameter while injection speed is the insignificant parameter.

- The contribution of parameters is melting temperature (52.4\%), holding pressure (3.6\%), holding time $(0.9 \%)$ and cooling time $(6.9 \%)$.

\section{Future Scope:}

Warpage: Some warp age can be expected with any molded plastic part. The amount of warpage will vary with the type of thermoplastic material being used. A good rule of thumb for most material and part configurations is .010 distortion per 3.00 part length $(.033 \mathrm{~mm} / \mathrm{cm})$.

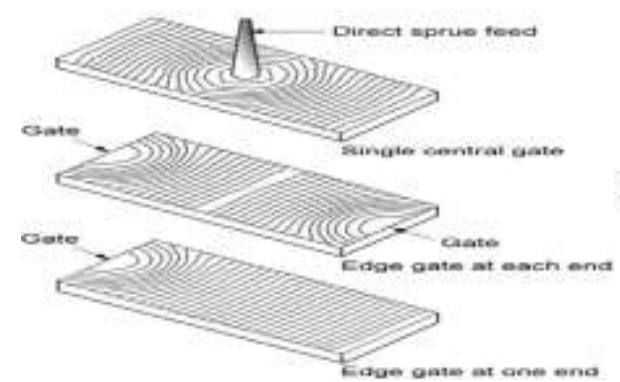

Figure 6: Material flow patterns

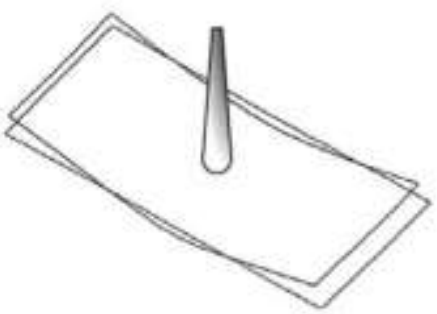

Figure 7: Predicted part warpage for centre-gated part

Compares three possible gate designs for a large rectangular part. For each gating design, computer simulation predicts the resultant filling pattern, as well as any potential warpage, weld lines or air entrapment. Figure 1a shows three different gating arrangements with their corresponding filling patterns. It is possible in many cases to visualize the filling patterns of straightforward parts, and this ability increases with experience.

Upon examining the computer predictions, one can make the following observations:

- The centre-gated design, shown in Figure: 6, produces a radial filling pattern consisting of both shear and elongational flows. Such a filling pattern introduces molecular orientation in both radial and tangential directions. If the volumetric shrinkage in these two directions is different, then warpage will occur. Figure 1b shows the predicted part warpage for the centre-gated design.

- The double edge gated design results in a weld line at the centre of the part. This could be undesirable from an appearance or functional point of view.

- The single edge gated design is the best of the three designs because it produces a unidirectional filling pattern with uniform molecular and fiber orientation [3].

\section{This could be a best input to the product designers, mould designers \& tool and die makers.}

Polishing in the Ejection Direction:

This is an important point because it is sometimes much easier to polish a mold core or cavity perpendicular to the direction of ejection. While the cylindrical core shown in Figure is most easily polished in a spinning lathe, it is important that at least the final polishing steps be done along the direction of part ejection (i.e. in the line of draw) [6].

Polishing perpendicular to the direction of ejection

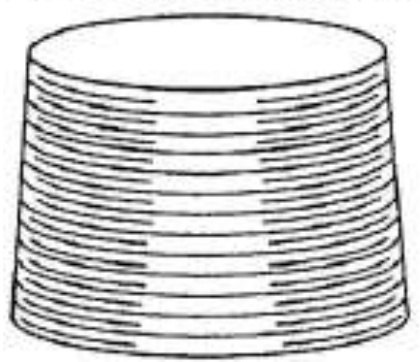

Figure8: Direction of polishing
Draw polishing reduces ejection force

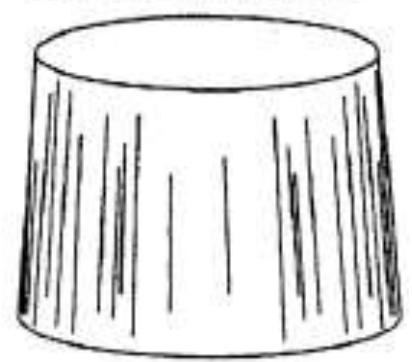




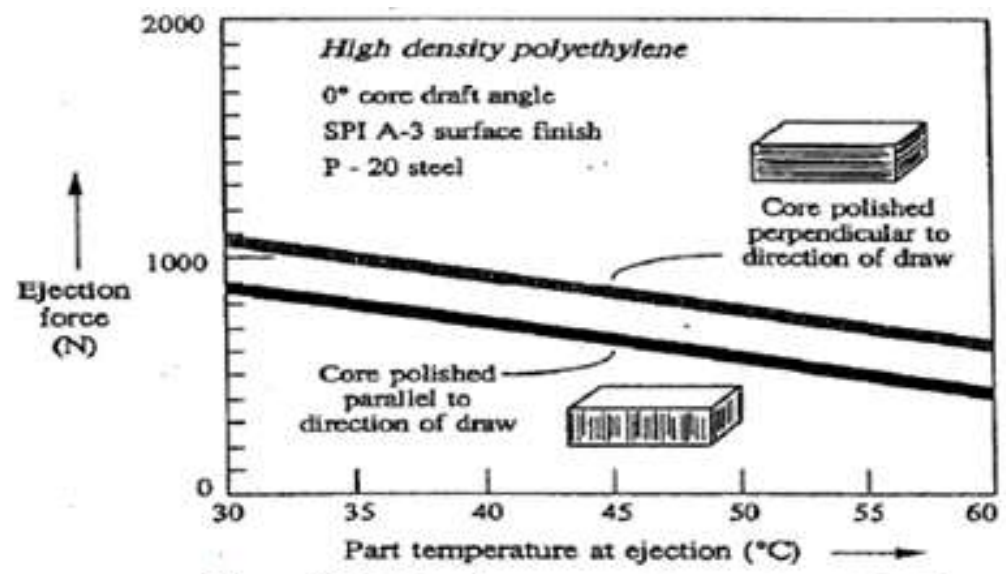

Figure9: Ejection force vs. part temperature at ejection

\section{Conclusion:}

By using the taguchi method/table is shown in below, by using this we can optimize the injection process parameters, using optimum process parameters we can achieve minimum shrinkage, which reduces the maximum warp age of plastic component. From the literature review the most affecting parameters (is the melting temperature, packing pressure and packing time) to the quality of the product. By adopting both taguchi method and as well as proper gate location and direction of polishing on core \&cavity, which results in maximum reduction of warpage/distortion of plastic component during molding. The gate location, direction of polish and cooling time, these are the factors going to effect the warpage of the plastic component

\section{- Orthogonal Array(OA):}

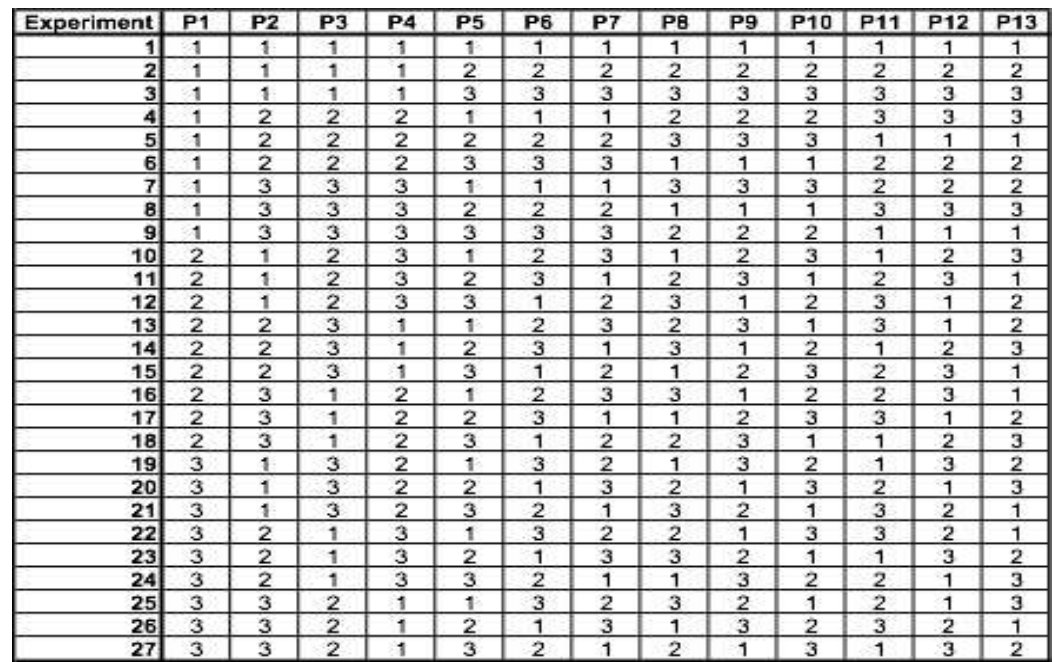

\section{References:}

[1] Brydson JA. Plastic material. Butter worth Heinmann;1955.

[2] Ross PJ.taguchi technique for quality engineering. McGraw Hill;1996.

[3] Mr.Peter Jones,the mold design guide;Smithers Rapra Technoligy Ltd. Publishers;2008

[4] S.Kamaruddin, Zahid A. Khan and S. H. Foong, Application of Taguchi Method in the Optimization of Injection Moulding Parameters for Manufacturing Products from Plastic Blend, IACSIT International Journal of Engineering and Technology, Vol.2, No.6, December 2010 ISSN: 1793-8236.

[5] Mr. A.J. Yadav1, Mrs. S.V. Dravid2 Mr. V.D. Rajput3,taguchi technique in optimization of injection molding process parameters for manufacturing plastic parts, Proceedings of the NCNTE-2012, Third Biennial National Conference on Nascent Technologies Fr. C. Rodrigues Institute of Technology, Vashi, Navi Mumbai, Feb 24-25, 2012 Department of Mechanical Engineering.

[6] Robert A.Malloy,Plastic part design for injection molding:MA 01854,USA 